\title{
Forum
}

\section{Mot en situerad standardisering inom socialtjänsten}

Alexander Björk, Fil.dr, forskare, Institutionen för socialt arbete, Stockholms universitet. Kontakt: alexander.bjork@socarb.su.se

\section{Inledning}

Under de senaste två decennierna har det ställts allt högre krav på standardiserad dokumentation och uppföljning inom socialtjänstens fält, både nationellt och internationellt (Socialstyrelsen, 2004; Tilbury, 2004; Lynch-Cerullo \& Cooney, 2011). Utvecklingen hänger ihop med övergripande strömningar som Evidensbaserad praktik (EBP) och New Public Management (NPM) som sätter fokus på att mäta effektiviteten av offentlig verksamhet utifrån kvantitativa mått. Den grundläggande idé som förts fram är att standardiserad dokumentation inom den reguljära verksamheten ska möjliggöra kontinuerlig mätning av socialtjänstens utfall, både på individuell och aggregerad nivå, och att informationen ska användas till att förbättra insatsernas kvalitet.

Genom att standardisera socialtjänstens dokumentation av klienter i kvantifierbara variabler, både mellan olika handläggare och över tid, ska det göra det möjligt att kvantitativt kartlägga klientgrupper och följa upp deras utfall. I likhet med strävanden om att utveckla EBP är det ett sätt att utveckla den vetenskapliga grunden i praktiskt socialt arbete, men en stor skillnad är att den här strategin bygger på en annan typ av kunskap. Medan EBP traditionellt betonar experimentell kunskap producerad genom till exempel randomiserade kontrollerade studier, bygger standardiserad dokumentation på information som samlas in i socialtjänstens vardagliga arbete, alltså en mindre kontrollerad typ av kunskap.

Inom ramen för standardiserad dokumentation har det förts fram en rad modeller och instrument som ska möjliggöra systematisk uppföljning. Exempel på modeller som diskuteras i Sverige är Goal Attainment Scaling (GAS), Single Systems Design 
(SSD), Lokal evidens (LOKE) och i viss mån Barnets Behov i Centrum (BBIC) (se Socialstyrelsen, 2014). Det gemensamma för modellerna är att de syftar till att formulera individualiserade mätbara mål som kan användas för att följa upp klienternas utveckling över tid. Det kan jämföras med standardiserade bedömningsinstrument som innehåller förbestämda frågor som ska ställas till alla klienter. De kan i sin tur delas upp i riskbedömningsinstrument - som beräknar risken för olika typer av skadlig utveckling - och bedömnings- och uppföljningsinstrument som kartlägger behov och problem vid initial bedömning och uppföljning, till exempel ASI, ADAD, DOK, DUR, CBCL, ESTER.

I den här artikeln kommer jag att fokusera på användningen av standardiserade bedömnings- och uppföljningsinstrument som ett sätt att följa upp klienter inom socialtjänstens reguljära arbete. Med utgångpunkt från praktiska exempel från forskningslitteraturen och teoretiska insikter inom sociologisk forskning om standarder kommer jag att diskutera problem med nuvarande arbete med standardiserade bedömningsinstrument och argumentera för ett nytt angreppssätt för forskning om och utveckling inom området.

Det centrala argumentet i artikeln är att standardiserade bedömnings- och uppföljningsinstrument, trots ihärdiga försök, inte används tillräckligt systematiskt för att möjliggöra valid uppföljning av klienter och insatser på aggregerad nivå. Jag föreslår därför att det krävs en ny inriktning i utvecklingen och införandet av dessa instrument. En viktig anledning till den osystematiska användningen är att instrumenten sällan är särskilt väl anpassade till de verksamheter där de är satta att användas. Instrumenten har i många fall testats noggrant för psykometriska egenskaper, det vill säga hur väl de mäter det de avser att mäta, men hur genomförbara de är eller hur väl de passar in i socialtjänstens arbete har i princip aldrig testats. Jag argumenterar därför för en "situerad standardisering" (Zuiderent-Jerak, 2015) av socialtjänstens dokumentation och uppföljning som ett nytt teoretiskt och metodologiskt sätt att närma sig frågan om standardiserad bedömning och uppföljning. Det innebär att vi inte kan nöja oss med att naivt anamma "färdiga" instrument i sin helhet, utan att vi måste testa hur de fungerar i praktiken och utifrån det göra nödvändiga anpassningar - alltså en standardisering av socialtjänstens dokumentation med hänsyn till praktikens förutsättningar.

\section{Osystematisk användning av standardiserade bedömningsinstrument}

Standardiserade bedömningsinstrument har av många politiska aktörer lyfts fram som en strategi att förbättra den vetenskapliga grunden i praktiskt socialt arbete (CUS, 1996; Socialstyrelsen, 2004; SOU 2008:18). Som ett led i den ambitionen har 
både Socialstyrelsen och Statens institutionsstyrelse varit med i utvecklingen och översättningen av standardiserade bedömningsinstrument (Jenner \& Segraeus, 2005; Nyström, Zingmark \& Jäderland, 2009). Redan år 1996 introducerades ett av de första instrumenten, ASI, i svenskt socialt arbete (Nyström, Zingmark \& Jäderland, 2009). Men för att lyckas hålla vad de lovar för att förbättra den vetenskapliga grunden i socialt arbete krävs det emellertid att instrumenten används systematiskt i praktiken, annars är informationen som samlas in av tveksamt värde.

Många av de studier som undersökt den faktiska användningen av standardiserade bedömningsinstrument inom socialtjänsten visar att de används i långt ifrån alla ärenden. De flesta studierna kommer från missbruksområdet, som är det område inom socialtjänsten med längst erfarenhet av standardiserade bedömningsinstrument (Sundell et al., 2008). Studier har visat att socialarbetare generellt sett förefaller vara positiva till standardiserade bedömningsinstrument och lyfter fram flera positiva aspekter (Spear, Hamilton Brown \& Rawson, 2005; Alexanderson, 2006; Abrahamson \& Tryggvesson, 2009; Björk, 2013). Många socialtjänstenheter rapporterar att de har en ambition att använda standardiserade bedömningsinstrument, men mer detaljerade frågor visar att instrumenten sällan används fullt ut. Till exempel används uppföljningsformulär betydligt mer sällan än intagningsformulär, och den information som samlas in genom formulären sammanställs och analyseras mycket sällan (ibid., Engström \& Armelius, 2005; Alexanderson, 2006; Abrahamson \& Tryggvesson, 2007; Björk, 2013). Mer aktuella siffror från öppna jämförelser inom missbruksområdet visar att bedömningsinstrument används för uppföljning i endast 16 procent av alla kommuner (Öppna jämförelser, 2016).

De flesta tillgängliga uppgifter visar alltså att användningen av standardiserade bedömningsinstrument är tämligen osystematiskt inom det område inom socialtjänsten där man har längst erfarenhet i frågan. Mot bakgrund av de stora resurser som har lagts ner i frågan, både på central statlig nivå och på socialtjänstenheter runt om i landet, finns det därför anledning att försöka förstå glappet mellan ambition och praktik och hitta andra vägar framåt.

\section{Osystematisk användning i ett sociologiskt perspektiv på standardisering}

I den här artikeln diskuterar jag frågan om standardiserad dokumentation utifrån en tradition som på engelska har benämnts "sociology of standards and standardization", och som hädanefter benämns sociologiska studier av standardisering (se Timmermans \& Epstein, 2010). Traditionen bygger på forskning från flera olika samhällsvetenskapliga fält, med särskild tonvikt på teknik- och vetenskapsstudier. Här definieras standardisering som "en process av skapande av likformighet i tid och rum 
genom formulerande av överenskomna regler" (ibid., s. 71). Definitionen ligger alltså i linje med ambitionen med standardiserade bedömningsinstrument som syftar till att skapa likformighet i hur socialtjänster dokumenterar sina klienter. Till skillnad från andra samhällsvetenskapliga traditioner, som ofta fokuserar på standarder som en form av styrning eller som en legitimitetsskapande aktivitet gentemot omgivande aktörer, fokuseras inom sociologiska studier av standardisering på själva innehållet i standarder och standardisering, till exempel utvecklingen, utformningen och införandet av standarder.

Frågan om standardisering är laddad och diskussionen blir ofta polariserad. Inom EBP, som till stor del kan beskrivas som ett standardiseringsprojekt, beskrivs det av förespråkare å ena sidan som en strategi för att motverka subjektivitet och godtycklighet. Kritiker å andra sidan, menar att det är en avhumanisering av det professionella arbetet (se Knaapen, 2014). Snarare än att inta en essentialistisk hållning till standarder och standardisering - som antingen alltigenom bra eller dåligt - intar man inom sociologiska studier av standardisering huvudsakligen ett empiriskt förhållningssätt. Härigenom är det möjligt att mer nyanserat analysera både positiva och negativa aspekter av specifika standarder i konkreta fall. Genom det här perspektivet argumenterar jag för en ny inriktning på arbetet med standardiserade bedömningsinstrument, inte att skrota idén i sin helhet, utan att skapa en annan typ av standardisering av socialtjänstens dokumentation.

\section{Standardisering och osynligt arbete}

En tidig insikt inom sociologiska studier av standardisering är att standarder inte är neutrala verktyg, utan att de inkluderar och exkluderar olika synvinklar (Bowker \& Star, 1999). Vad gäller standardisering av arbetspraktiker beror det på vilka aspekter som formellt lyfts fram som arbete (Star \& Strauss, 1999). Inom sjukvården, till exempel, tenderar läkarens arbetsuppgifter att lyftas fram, medan undersköterskors arbeten ofta tas för givna och osynliggörs - detta trots att undersköterskornas arbete är en förutsättning för att läkarnas arbete ska kunna utföras (Star, 1991). Allt arbete har mer eller mindre synliga och osynliga aspekter och inom utveckling av standarder är det vanligt att utgå ifrån en tämligen grund analys av arbetet och endast fokusera på de mer synliga och ofta mer "rationella" aspekterna. Det är problematiskt för standardens funktionalitet eftersom det är i det osynliga arbetet som oväntade problem, motsägelser och otillräcklig kunskap hanteras för att kunna slutföra en arbetsuppgift (Gerson \& Star, 1986; Berg, 1997, 1998).

När man utvecklar och använder standardiserade bedömnings- och uppföljningsinstrument är synligt och osynligt dokumentationsarbete en viktig aspekt. Att införa de här instrumenten syftar huvudsakligen till att vetenskapliggöra socialtjänstens 
dokumentation. Instrumenten lyfter fram mätbara variabler (per definition synliga) som ur ett strikt vetenskapligt perspektiv är de mest relevanta att veta om klienternas behov och problem, och testar sedan huruvida de är psykometriskt hållbara. Många av de instrument som man nu tänker sig ska användas inom socialtjänsten (Addiction Severity Index, ADAD, CBCL) har utvecklats inom forskningssammanhang, utan någon ursprunglig tanke om att de ska användas inom socialtjänstens vardagliga arbete. Det här illustrerar att instrumenten förkroppsligar ett vetenskapligt perspektiv.

Det som hittills har ignorerats är att instrumenten införs i ett sammanhang med redan befintliga traditioner där också dokumentationen måste förhandlas i relation till andra aspekter av klientarbetet. Det kan sägas vara en osynlig aspekt av socialtjänstens dokumentation som är svår att identifiera utan nära förtrogenhet med det här arbetet. En aspekt av det handlar om vad socialtjänsten egentligen behöver dokumentera för att kunna utföra sitt arbete på ett bra sätt. Många av de nuvarande instrumenten tenderar att vara mer omfattande än nödvändigt, vilket innebär att de tar viktig tid från handläggarnas arbete och inte alltid uppfattas som relevanta. En annan aspekt handlar om vilka förutsättningar det finns att följa upp klienter, och på vilket sätt det ska göras. Många beskrivningar av standardiserade bedömningsinstrument menar att det ska göras med ett fast tidsintervall, till exempel var sjätte månad (Socialstyrelsen, 2004). Socialtjänstens uppföljningsarbete förefaller dock inte följa den temporala strukturen, utan handläggarna följer huvudsakligen upp i samband med att något har skett i klientens vårdkedja: nya insatser, återfall, sammanbrott och så vidare (Björk, 2013).

De huvudsakligen osynliga aspekterna av socialtjänstens dokumentation är viktiga för att förstå hur nuvarande bedömningsinstrument kan användas i praktiken. Det är emellertid inte ett argument för att bevara rådande dokumentationspraktiker, utan snarare att det är möjligt att skapa en standardisering som utöver ett vetenskapligt perspektiv även tar hänsyn till handläggarnas perspektiv och socialtjänstens praktiska förutsättningar.

\section{Goda organisatoriska skäl till osystematisk användning?}

Så hur kan vi förstå socialtjänstens osystematiska användning av standardiserade bedömningsinstrument? Utifrån ett traditionellt implementeringsperspektiv brukar det tolkas antingen som att det finns ett motstånd mot det som ska implementeras eller som att "implementering tar tid", det vill säga vi har inte försökt tillräckligt länge. I den första tolkningen visar forskningen, som nämndes ovan, att socialarbetare generellt verkar vara positiva till standardiserade bedömningsinstrument. I den andra tolkningen, kan det vara värt att påpeka att vi har att göra med en idé som socialtjänsten 
har försökt att införa i över tio år (ASI har t.ex. funnits i Sverige i över 20 år) utan att generera några övertygande resultat i praktiken. Förklaringsmodellerna bygger på en traditionell förståelse av hur implementering bör gå till, nämligen att lokala verksamheter ska utföra beslut som fattats av politiker och chefer (Fernler, 2012). Här fokuserar man framförallt på de lokala verksamheternas följsamhet och inte på idéerna eller objekten som ska implementeras.

Inom sociologiska studier av standardisering fokuserar man både på de lokala verksamheterna och på objekten som ska implementeras. Ett återkommande resultat som har blivit något av ett mantra är att "standardens specifika utformning är betydelsefull" (Timmermans \& Epstein, 2010, s. 83). Utifrån det perspektivet kan en viktig förklaring till den osystematiska användningen finnas i själva utformningen av standardiserade bedömningsinstrument. Som nämndes ovan är det framförallt den vetenskapliga synvinkeln som har premierats när man utformat instrumenten och det vardagliga dokumentationsarbetet har inte fått komma till tals i någon större utsträckning. Det har resulterat i instrument som inte är anpassade till den typ av arbete där de är tänkta att användas och därför är svåra att tillämpa systematiskt.

I en etnografisk studie av en missbruksenhet inom socialtjänsten som är relativt framgångsrik i sin implementering av Addiction Severity Index (ASI), är det ett tydligt resultat. Trots att socialarbetarna är positivt inställda till instrumentet och trots att man systematiskt implementerat det över flera års tid, finns det fortfarande bristande systematik i användningen av ASI (Björk, 2013). Enheten är visserligen en av de bättre i Sverige vad gäller implementeringen, men uppföljningsformuläret används som mest i 47 procent av alla ärenden, och i 30 procent av fallen är det osäkert om det rörde sig om en "riktig" uppföljning eller om en ny initial bedömning. I kombination med att det inte finns tillräcklig information för att göra bortfallsanalyser blir det svårt att veta vad uppföljningar på aggregerad nivå egentligen betyder.

Deltagande observationer och intervjuer på enheten och intervjuer med socialarbetarna visar att intagningsformuläret uppskattas och fyller en viktig roll i deras utredningsarbete, men att motsvarande inte gäller för uppföljningsformuläret. Regelbundna uppföljningar görs av socialarbetarna, men då utifrån några få frågor som rör klientens specifika behov, insatser och stöd, frågor som ger utrymme för klienternas egna berättelser (jfr Martinell Barfoed, 2014). I det arbetet uppfattas uppföljningsformuläret med sina 120 kvantitativa frågor som otympligt och som en uppföljning "för sakens skull" och inte för att hjälpa klienten. Här blir det tydligt att det vardagliga uppföljningsarbetet sker och förhandlas i relation till övriga principer i klientarbetet, varav den tydligaste principen i det här fallet är "att hjälpa". Det här är ett exempel på en aspekt av det vardagliga dokumentationsarbetet som hittills har varit osynliggjord när man diskuterat standardiserade bedömningsinstrument och utformningen av dem. Med en bättre förståelse för de praktiska förutsättningarna för 
socialtjänstens uppföljningsarbete, hade uppföljningsformuläret kunnat vara betydligt mindre omfattande, dels eftersom all information inte uppfattas som nödvändig för handläggarnas arbete, dels eftersom det skulle vara enklare att få in i det vardagliga arbetet.

Utan kännedom om det hittills osynliga arbetet kan socialtjänstens osystematiska användning av standardiserade bedömningsinstrument framstå som irrationellt, men från ett inifrånperspektiv är det möjligt att se "goda organisatoriska skäl" till det, något som Garfinkel (1967) konstaterade redan för 50 år sedan. Ansvaret för den osystematiska användningen kan alltså inte enbart läggas på socialtjänsten, utan bör snarare förstås utifrån hur väl instrumenten fungerar med användarnas vardagliga arbete.

I stället för att enbart fokusera på hur socialtjänsten kan förbättra sin implementering, bör vi alltså även fokusera på hur de standardiserade bedömningsinstrumenten bättre kan anpassas till sina användare. Det här innebär inte att vi ska premiera socialtjänstens perspektiv framför det vetenskapliga perspektivet, utan snarare att de bör anpassas ömsesidigt till varandra. Det ligger i linje med situerad standardisering som presenteras i nästa del.

\section{Mot en situerad standardisering av socialtjänstens dokumentation}

Den här artikeln för fram begreppet situerad standardisering som ett alternativt sätt att standardisera socialtjänstens dokumentation utifrån sina egna förutsättningar. Det är ett begrepp som inkorporerar några av de övergripande insikter inom sociologiska studier av standardisering som diskuterats i artikeln. Begreppet, som myntats av Teun Zuiderent-Jerak (2015), pekar på att all standardisering sker utifrån ett visst perspektiv eller en viss position, det finns alltså ingen standardisering från ingenstans, utan standarder är alltid situerade i någon mån (jfr Haraway, 1988; Jerak-Zuiderent, 2015). Till exempel är nuvarande standardiserade bedömningsinstrument - hur objektiva de än kan framstå - situerade i ett vetenskapligt perspektiv på vilka och hur många frågor som är relevanta att bedöma och följa upp av ett visst problem. Argumentet i artikeln är att vi tydligare bör situera standardiseringen i det praktiska arbetet där standarden är tänkt att användas, det vill säga utifrån socialtjänstens perspektiv, behov och förutsättningar. Det kan de facto vara ett sätt att undvika att "lösningar" formuleras utanför de praktiker som de relaterar till och senare ska implementeras i. Situerad standardisering kan då beskrivas som ett sätt att undvika implementering (Zuiderent-Jerak, 2007).

Zuiderent-Jerak har utvecklat begreppet genom en rad projekt inom hälso- och sjukvården där han deltagit inte bara som forskare utan även som aktiv deltagare $\mathrm{i}$ olika former av standardiseringsarbeten. I ett av projekten arbetade han med att ana- 
lysera och försöka förbättra arbetsflödet inom onkologi- och hematologivården på ett holländskt universitetssjukhus (Zuiderent-Jerak, 2007). Ett vanligt sätt att hantera det här problemet är att implementera så kallade integrerade vårdplaner (integrated care pathways) som har blivit ett populärt sätt att standardisera patienternas vårdvägar. Enligt beskrivningen av modellen ska integrerade vårdplaner utvecklas och implementeras genom att följa en detaljerad manual, vilket alltså är ett sätt att definiera lösningar utanför den kontext där vårdplanen ska iscensättas. I stället valde Zuiderent-Jerak ett mer processuellt angreppssätt där han utifrån både kvantitativa analyser och etnografisk forskning inom de berörda enheterna på sjukhuset analyserade problemen och försökte hitta lösningar på dem. Genom etnografiska metoder är det alltså möjligt att få en djupare förståelse för arbetet som ska utvecklas och att artikulera även de funktionellt "osynliga" synvinklarna (jfr Star \& Strauss, 1999). De lösningar som konstruerades utifrån den inledande forskningen betraktades emellertid inte som färdiga, utan snarare som förslag som enheten kunde experimentera med för att hitta en slutlig lösning som fungerade i praktiken och som de olika professionella grupperna inom enheten kunde enas om. Bland annat skapades ett flödesschema som sammanfattade de strukturella komponenterna i patientgruppernas vårdvägar, något som blev en utgångspunkt för utvecklingsarbetet och som omformulerades efter de professionellas förslag.

Det här illustrerar en situerad standardisering där vi kan undvika implementering och de problem som de ofta för med sig. Medan standardisering och situerat handlande ofta betraktas som varandras motpoler, visar detta att det är möjligt att i större grad ta hänsyn till lokala, kontextuella förhållanden när man utvecklar standarder. Det här innebär inte en "lättare" form av standardisering eller ett mellanting mellan standardisering och situerat handlande, utan snarare att standardiseringen sker från ett annat håll med större hänsyn till socialtjänstens perspektiv.

\section{Implikationer för forskning och utveckling}

Så, hur kan vi överföra det här till forskningen om och utvecklingen av standardiserade bedömningsinstrument inom socialtjänsten?

Sociologiska studier av standardisering och begreppet situerad standardisering pekar på en ny inriktning inom forskningsområdet där det är möjligt att empiriskt analysera innehållet $\mathrm{i}$ standardiserad dokumentation, och inte enbart som en projektionsyta för professionell och organisatorisk legitimitet. När standardisering diskuteras inom forskning i socialt arbete sker det ofta som en motpart till professionellt handlingsutrymme (se Björk, 2016; Ponnert \& Svensson, 2016). Utifrån det perspektivet kan vi få en mer finkornig bild av hur specifika dokumentationsstandarder påverkar, vilka aspekter av handlingsutrymmet som påverkas samt i vilka kontexter 
det sker. Begreppet situerad standardisering belyser för det första att standardisering kan anta en mängd olika skepnader och för det andra att det inte nödvändigtvis står i motsatsförhållande till professionellt arbete.

När vi utvecklar standardiserade bedömningsinstrument innebär situerad standardisering att vi måste ta större hänsyn till socialtjänstens specifika kontext. Jag menar emellertid inte att det är ett argument för att alla socialtjänstenheter ska ha olika dokumentationsstandarder, utan snarare att bedömningsinstrumenten i större grad bör ta hänsyn till typiska eller gemensamma aspekter av socialtjänstens arbete. Två sådana aspekter som aktualiserats i min egen forskning är hur tidspress och sammanbrott $\mathrm{i}$ behandling och insatser kan hanteras $\mathrm{i}$ bedömning och uppföljning av klienter. Vad det gäller tidspress så är ett vanligt fynd att socialarbetare inte upplever sig ha tid att använda bedömningsinstrument, vilket kan vara en anledning till att fundera över hur många frågor som bör inkluderas i instrumenten. Färre frågor är rimligtvis lättare att inkludera i socialarbetarnas pressade arbete. Vad det gäller den andra aspekten, så är sammanbrott eller oplanerade avbrott $\mathrm{i}$ behandling och stöd ett vanligt fenomen inom socialtjänstens olika verksamheter. Det gör uppföljningsarbetet svårare, för när är det egentligen lämpligt att göra en uppföljning: utifrån ett visst tidsintervall, vid, eller efter avslutad insats? Någon form av standardisering av uppföljningen är viktig för att det ska kunna gå att dra några slutsatser av aggregerade data. Det här är två aspekter som delas av många verksamheter inom socialtjänsten som kan behöva uppmärksammas för att utveckla en situerad standardisering av dokumentation och uppföljning.

En annan relaterad implikation är att vi inte bör se standardiserade bedömningsoch uppföljningsinstrument som färdiga lösningar för socialtjänstens arbete. Bara för att ett instrument har visat sig ha goda psykometriska egenskaper eller visat sig förbättra utredningskvaliteten innebär det inte att det är användbart eller genomförbart inom socialtjänsten. De aspekterna är visserligen viktiga om vi vill förbättra socialtjänstens dokumentation, men om vi inte funderar över hur väl ett instrument kan användas i praktiken kommer det inte att leda till önskvärd standardisering av det dagliga arbetet. Vi bör även testa instrumentens genomförbarhet i praktiken och utifrån det göra önskvärda förändringar. Det är något som även diskuterats inom folkhälsoområdet under benämningen feasibility studies, eller på svenska 'genomförbarhetsstudier' (se Bowen et al., 2009).

Situerad standardisering pekar emellertid inte enbart på strategier för att anpassa befintliga instrument, utan kan även tillämpas för att utveckla nya instrument. I det arbetet bör lika stort vetenskapligt fokus läggas på att testa genomförbarhet som att testa psykometriska egenskaper. Utifrån exemplen som diskuterats i artikeln blir det tydligt att det krävs flera forskningsmetoder för att utveckla och anpassa standardiserade bedömningsinstrument. Utöver kvantitativa mätningar av hur ofta instrumen- 
ten används och intervjuer med socialarbetare om hur de ser på instrumenten, finns det även ett behov av att faktiskt observera och få en förstahandsupplevelse av det dagliga dokumentationsarbetet. Annars riskerar vi att bli utelämnade åt rationaliseringar och socialt önskvärda svar.

\section{Referenser}

Abrahamson, M. \& Tryggvesson, K. (2007) Användning av bedömningsinstrument i missbrukarvården - en nationell kartläggning och fallstudier av två län. Stockholm: Stockholms universitet, Centre for Social Research on Alcohol and Drugs (SoRAD) \& Socialstyrelsen.

Abrahamson, M. \& Tryggvesson, K. (2009) Socialtjänstens användning av standardiserade klientbedömningsinstrument-ASI som retorik och praktik i två svenska kommuner. Nordic Studies on Alcohol and Drugs, 26(1): 21-39.

Alexanderson, K. (2006) Vilja kunna förstå: Om implementering av systematisk dokumentation för verksamhetsutveckling $i$ socialtjänsten. Akademisk avhandling. Örebro: Örebro universitet.

Berg, M. (1997) Rationalizing medical work: Decision-support techniques and medical practices. Cambridge: MIT Press.

Berg, M. (1998) The politics of technology: On bringing social theory into technological design. Science, Technology \& Human Values, 23(4): 456-490.

Björk, A. (2013) Working with different logics: A case study on the use of the Addiction Severity Index in addiction treatment practice. Nordic Studies on Alcohol and Drugs, 30(3): 179-199.

Björk, A. (2016) Evidence-based practice behind the scenes: How evidence in social work is used and produced. Akademisk avhandling. Stockholm: Stockholms universitet.

Bowen, D.J. et al. (2009) How we design feasibility studies. American Journal of Preventive Medicine, 36(5): 452-457.

Bowker, G.C. \& Star, S.L. (1999) Sorting things out: Classification and its consequences. Cambridge: MIT Press.

Centrum för utvärdering av socialt arbete, CUS. (1996) Dokumentation inom missbrukarvården: Behandlingsarbete, metodutveckling, utvärdering (1 uppl.). Stockholm: Centrum för utvärdering av socialt arbete (CUS).

Engström, C. \& Armelius, B.- $\AA$. (2005) Implementering av en strukturerad intervju (ASI) i missbruksvård och kriminalvård. Socialvetenskaplig tidskrift, 12(1): 27-42.

Fernler, K. (2012) Perspektiv på implementering: Vad är "god" implementering och kan det stödjas? Leading Health Care, 8.

Garfinkel, H. (1967) Studies in ethnomethodology. New Jersey: Prentice Hall

Gerson, E. \& Star, S.L. (1986) Analyzing due process in the workplace. ACM Transactions on Office Information Systems, 4(3): 257-270.

Haraway, D.J. (1988) Situated knowledges: The science question in feminism and the privilege of partial perspective. Feminist Studies, 14(3): 575-599.

Jenner, H. \& Segraeus, V. (2005) The Swedish DOC-System - An attempt to combine documentation and self-evaluation. European Addiction Research, 11(14): 186-192.

Jerak-Zuiderent, S. (2015) Accountability from somewhere and for someone: Relating with care. Science as Culture, 24(4): 412-425.

Knaapen, L. (2014) Evidence-based medicine or cookbook medicine? Addressing concerns over 
the standardization of care. Sociology Compass, 8(6): 823-836.

Lynch-Cerullo, K. \& Cooney, K. (2011) Moving from outputs to outcomes: A review of the evolution of performance measurement in the human service nonprofit sector. Administration in Social Work, 35(4): 364-388.

Martinell Barfoed, E. (2014) Standardiserad interaktion - en utmaning för socialt arbete. Socialvetenskaplig tidskrift, 21(1): 4-23.

Nyström, S., Zingmark, D. \& Jäderland, A. (2009) ASI-manualen - Anvisningar till

ASI Grund och ASI Uppföljning. Stockholm: Institutet för metodutveckling i socialt arbete (IMS).

Ponnert, L. \& Svensson, K. (2016) Standardisation - the end of professional discretion? European Journal of Social Work, 19(3-4): 586-599.

Socialstyrelsen (2004) Systematisk bedömning inom socialtjänsten. Stockholm: Institutet för metodutveckling i social arbete.

Socialstyrelsen (2014) Systematisk uppföljning. Beskrivning och exempel. Stockholm: Socialstyrelsen. SOU 2008:18. Evidensbaserad praktik inom socialtjänsten - till nytta för brukaren. Stockholm: Fritzes.

Spear, S.E. \& Hamilton Brown, A. \& Rawson, R.A. (2005) "Painting a picture of the client": Implementing the Addiction Severity Index in community treatment programs. Journal of Substance Abuse Treatment, 29(4): 277-282.

Star, S.L. (1991) The sociology of the invisible. The primacy of work in the writings of Anselm Strauss. I: D. Maines (red.), Social organization and social process: Essays in honor of Anselm Strauss. Hawthorne: Aldine de Gruyter.

Star, S.L. \& Strauss, A. (1999) Layers of silence, arenas of voice: The ecology of visible and invisible work. Computer Supported Cooperative Work, 8: 9-30.

Sundell, K., Brännström, L., Larsson, U. \& Marklund, K. (2008) På väg mot en evidensbaserad praktik. Stockholm: Socialstyrelsen.

Tilbury, C. (2004) The influence of performance measurement on child welfare policy and practice. British Journal of Social Work, 34(2): 225-241.

Timmermans, S. \& Epstein, S. (2010) A world of standards but not a standard world: Toward a sociology of standards and standardization. Annual Review of Sociology, 36: 69-89.

Zuiderent-Jerak, T. (2007) Preventing implementation: Exploring interventions with standardization in healthcare. Science as Culture, 16(3): 311-329.

Zuiderent-Jerak, T. (2015) Situated intervention: Sociological experiments in health care. Cambridge: MIT Press.

Öppna Jämförelser (2016) Missbruks- och beroendevården. [http://www.socialstyrelsen.se/ SiteCollectionDocuments/oppna-jamforelser-2016-missbruks-och-beroendevarden-resultatsamtliga-kommuner.xls.] 